\title{
Public Health 2016: time for a cultural shift in the field of public health
}

\author{
E. R. M. Mallach, MSc (1); T. Ferrao, MSc (1); R. MacLean, MPH (1); S. F. L. Kirk, PhD (2)
}

Tweet this article

Public Health 2016, the Canadian Public Health Association's annual conference, was held from June 13 to 16, 2016, in Toronto, Canada, and showcased a wide variety of public health issues that fostered considerable discussion at the conference and on social media., ${ }^{1,2}$ The four plenary sessions, while on seemingly disparate topics including technology, violence prevention, racism and harm reduction, all revealed the need for a cultural shift in the field of public health that acknowledges and addresses the broader inequities that influence the health and well-being of populations. They also highlighted some of the key challenges that society faces in achieving the UN Sustainable Development Goals released in $2015 .^{3}$

The impact of the social determinants of health is widely acknowledged in the field of public health, yet much work remains to effectively address these social, economic and environmental factors through policy change and program intervention. Further, while the dominant public health discourse acknowledges the role of income, employment and education, it often skirts around broader social inequities such as racism and structural violence, thereby perpetuating the very same health disparities the field is trying to lessen.

The opening ceremony at Public Health 2016 featured introductory remarks by Dr. Camara Jones, the president of the American Public Health Association, who spoke persuasively on the impact of racial disparities, privilege and power as they relate to health inequities. Dr. Jones used the powerful allegory of a two-sided sign displayed in a restaurant window shortly following closing: those within the restaurant enjoying their meal see the "Open" side, while hungry individuals passing by the restaurant see the "Closed" side. This allegory very effectively illustrates how social inequities such as racism create a dual reality whereby individuals on opposite sides of the "Open-Closed" sign receive differential access to opportunities, ultimately maintaining population health inequities.

Dr. David Buckeridge gave the opening plenary on technology and public health. He organized his presentation around three points: big data, going mobile and take-home thoughts. Dr. Buckeridge discussed the opportunity to harness technology and monitor health at a population level given the large amounts of available data. He used several examples to demonstrate the potential of mobile technology to promote health and underlined the advantages of technology, including its broad reach at a low cost, a reduced need for direct contact and its efficiency for communicating health information. The interventions Dr. Buckeridge discussed were focussed on individual behaviour change rather than the social determinants of health. Despite promising signs at the individual level, there is little evidence to suggest that technology can improve health equity at the population level. This represents an important gap in the literature, and an area worth exploring within public health.

The second plenary session was a panel on violence prevention, including an international, regional and Indigenous peoples' perspective. Given its high prevalence in Canada, the speakers made a clear and compelling case for the public health sector to address violence and its devastating consequences, which are clearly linked to the social determinants of health.

The speakers acknowledged that violence is a systemic problem that disproportionately affects certain subpopulations. Alessandra Guedes, Pan American Health Organization, stated that one in three women will experience partner violence or sexual violence by a non-partner in their lifetime. ${ }^{4}$ Looking even deeper, Sylvia Maracle, Ontario Federation of Indigenous Friendship Centres, noted an Indigenous woman in Canada has a seven or eight in 10 chance of being a victim of some form of violence. Beyond the immediate impacts of these violent acts, including an increased likelihood of injury and death, women are more likely to endure mental as well as sexual and reproductive health consequences.

Given the pervasive problem of violence in society, action is needed to increase access to safe and supportive services for those individuals who have experienced violence, and to prevent interpersonal as well as structural violence altogether. As a very first step in addressing violence, the public health field needs to take a lead role in acknowledging violence as a public health issue necessitating immediate action. Etienne Krug, World Health Organization, noted that the public health community has important contributions to make, as violence is largely preventable through appropriate interventions. Further, by addressing issues such as early childhood development, alcohol misuse, drug abuse and ensuring appropriate legislation on firearms, the public health community can contribute to violence prevention in Canada. When violence does occur, appropriate services must be available to 
those in need: the plenary speakers highlighted that although women who have experienced violence often use health services more frequently, they do not always disclose their experience of violence to their service provider. Increasing training of health and social service providers is a requisite to ensure that service providers are prepared to respond to individuals' needs in such a way that does not further contribute to trauma, an area where the public health field has shown considerable leadership.

The third plenary session focussed on health equity, social justice and the racialization of Canadian society. Building on many of the ideas presented during the violence prevention plenary, a diverse panel of experts discussed how racism is structurally embedded and propagated through Canadian practices, programs and policies. The speakers described racialization as a social construct whereby individuals receive differential opportunities based on their perceived membership in a racial community. Take the case of Canada's Indian Act, which was enshrined by the federal government in 1876 to govern relations with First Nations peoples but, in doing so, created the conditions to exert enduring control over First Nations populations and uphold inequities. ${ }^{5}$ The panellists made a clear link between racism and health. Desmond Cole, a freelance journalist, described racism as a legitimate stressor with resultant health implications and related this to his experience of targeted violence based on the colour of his skin. Dr. Ingrid Waldron, Dalhousie University, highlighted that race shapes how individuals are diagnosed and treated, emphasizing the disproportionate number of black men diagnosed with schizophrenia as an example.

The panellists offered some suggestions for moving forward, including an indelible cultural shift within society that acknowledges and addresses racism as a social determinant of health. Doing so will provide an opportunity for public health to demonstrate leadership in Canada's much needed response to racism. Dr. David McKeown, Toronto Public Health, acknowledged that the privilege afforded to nonracialized groups in Canada and globally is often not evident to those who have it, but that the public health community has an important role to play in shedding light on the structures that uphold privilege and power for non-racialized groups. Dr. Waldron suggested that the public health community should collaborate with those outside of the health system in an effort to bring different views to the discussion. As stated by Dr. Charlotte Loppie, Centre for Indigenous Research and Community-Led Engagement at the University of Victoria, although there is still much progress to be made, we have come a long way from where we were just three to five years ago, when racism was not part of the dominant public health discourse in Canada.

Canada's Chief Public Health Officer, Dr. Gregory Taylor, delivered the final plenary on harm reduction, risk perception and alcohol. Harm reduction recognizes that while risks cannot be completely eliminated, negative outcomes associated with risky behaviours can be significantly reduced. Dr. Taylor acknowledged that public health is founded in a philosophy of harm reduction. While harm reduction has at times inappropriately been labelled as controversial, particularly with respect to substance use, there is no question it saves lives. There are important links between harm reduction and other areas of public health, including violence prevention, seatbelt laws, travel advice and physical activity guidelines. In 2012, there were over 3.3 million alcohol-related deaths worldwide, ${ }^{6}$ confirming that public health has an important role to play in this area. Dr. Taylor went on to stress that if public health is to maintain its relevance and credibility, it needs to carefully consider how its messaging and outreach tactics affect risk perception and risk tolerance from a public perspective. Confusing, contradictory and paternalistic public health advice will erode public trust in the long term, cause the public to "tune-out" public health messaging and, ultimately, make it more difficult to achieve harmreduction goals.

The plenaries at Public Health 2016 revealed the need for a cultural shift in the field of public health that acknowledges the broader social inequities that underpin health, including racism and violence, and that addresses the practices, programs and policies embedded within Canadian society that uphold power and privilege and, in turn, promote health inequities. By acknowledging that racism and violence need to be addressed by the public health community, we are taking a clear position. We are recognizing that we are all part of a society that perpetuates health inequities, but we can also work towards lasting solutions. The discussions held at Public Health 2016 were a steppingstone, but refined action is now needed. Public health must build bridges in an effort to increase collaboration with other sectors and ultimately contribute to health equity. Public health has a role to play in facilitating the change we so desperately need and seek and, 30 years after the release of the Ottawa Charter for Health Promotion, public health in Canada can lead the way.

\section{Acknowledgements}

We would like to thank Ian Culbert for reviewing the draft paper.

\section{References}

1. Canadian Public Health Association. Public Health 2016 - highlights [Internet]. Ottawa (ON): Canadian Public Health Association; 2016 [cited 2016 Jun 24]. Available from: https:// storify.com/CPHA/public-health -2016-the-annual-conference-of-the-ca

2. Ndumbe-Eyoh S. Public Health 2016 plenary: health equity, social justice and the racialization of Canadian society [Internet]. Toronto (ON); 2016 [cited 2016 Jun 27]. Available from: https://storify.com/sumeeyoh/ plenary

3. United Nations. Sustainable development goals [Internet]. New York (NY): United Nations; 2015 [cited 2016 Jul 25]. Available from: https:// sustainabledevelopment.un.org $/$ ?menu $=1300$

4. World Health Organization. Violence against women: intimate partner and sexual violence against women. Fact sheet No. 239 [Internet]. Geneva, Switzerland: WHO; 2016 Jan [cited 2016 Jul 18]. Available from: http:// www.who.int/mediacentre/factsheets /fs239/en/

5. Loppie S, Reading C, de Leeuw S. Aboriginal experiences with racism and its impacts [Internet]. Prince George (BC): National Collaborating Centre for Aboriginal Health; 2014 [cited 2016 Jul 18]. Available from: http: / / w w w. nc cah-ccnsa.ca /Publications/Lists/Publications /Attachments/131/2014_07_09_FS _2426_RacismPart2_ExperiencesImpacts _EN_Web.pdf

6. World Health Organization. Global status report on alcohol and health 2014 edition. Geneva, Switzerland: WHO Press; 2014. 